\title{
Profile of acotiamide in the treatment of functional dyspepsia
}

This article was published in the following Dove Press journal:

Clinical and Experimental Gastroenterology

6 April 2016

Number of times this article has been viewed

\author{
Masahiro Ueda' \\ Eisuke Iwasakil \\ Hidekazu Suzuki² \\ 'Department of Internal Medicine, \\ Division of Gastroenterology and \\ Hepatology, ${ }^{2}$ Medical Education \\ Center, Keio University School of \\ Medicine, Tokyo, Japan
}

\begin{abstract}
Efficacy of acotiamide for improving symptoms in patients with functional dyspepsia was shown by several clinical trials. In a randomized, double-blind, placebo-controlled, parallelgroup comparative Phase III trial conducted in Japan, $100 \mathrm{mg}$ of acotiamide three times a day for 4 weeks was more effective than a placebo for improving symptoms, and quality of life. Acotiamide was well-tolerated treatment, with no significant adverse events. The aim of this review was to summarize the current evidence of the efficacy of acotiamide in the treatment of patients with functional dyspepsia.
\end{abstract}

Keywords: functional dyspepsia, acotiamide, acetylcholinesterase, Rome III

\section{Introduction}

Acotiamide, a novel oral prokinetic drug, was developed by Zeria Pharmaceutical Co., Ltd. (Tokyo, Japan) for treatment of patients with functional dyspepsia (FD). ${ }^{1,2}$ FD is a functional gastrointestinal disorder with upper abdominal symptoms, such as postprandial fullness, upper abdominal distension, and early satiety from the gastroduodenal area despite any existence of organic disorders. Additionally, FD is divided into two classes: postprandial distress syndrome (PDS) and epigastric pain syndrome. Duration of symptom is defined by an international diagnostic criteria (Rome III criteria). Criteria should be fulfilled for the last 3 months. Onset should be at least 6 months before diagnosis. Acotiamide modulates upper gastrointestinal motility to alleviate abdominal symptoms resulting from hypomotility. Acotiamide was launched in Japan in June 2013 as a therapeutic agent for FD. A Phase III trial was commenced in Europe, and a Phase II trial was finished in the USA. This review was conducted to summarize the updated current evidence just after the publication of meta-analysis, ${ }^{3}$ and to critically evaluate the efficacy as well as adverse effects of acotiamide in the treatment of patients with FD.

\section{Treatment for FD}

The name of clinical conditions that present symptoms such as epigastric pain and epigastric distress have been changing. In the 1960s, along with advancement of endoscopic diagnosis, the concept of "chronic gastritis" was intensively used. In the 1980s, prokinetic dysfunction attracted attention, and it was then called as non-ulcer dyspepsia. And in 1999, it was called FD. Disorders of gastrointestinal motility are considered a major pathophysiological mechanism underlying symptoms of FD. ${ }^{4}$

Many agents have been designed to stimulate muscle activity to improve hypomotilityassociated symptoms with gastrointestinal disorders such as delayed gastric empting,
Correspondence: Hidekazu Suzuki

Medical Education Center, Keio University School of Medicine,

35 Shinanomachi, Shinjuku-ku,

Tokyo 160-8582, Japan

Tel $+8 \mid 353633914$

Fax +8I 353633967

Email hsuzuki.a6@keio.jp
Clinical and Experimental Gastroenterology 2016:9 83-88

(c) (1) (8) ๑ 2016 Veda et al. This work is published and licensed by Dove Medical Press Limited. The full terms of this license are available at hitps://www.dovereses.com/terms.php cc. hereby accept the Terms. Non-commercial uses of the work are permitted without any further permission from Dove Medical Press Limited, provided the work is properly atributed. For peminsion

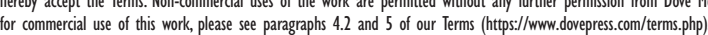

Dovepress

http://dx.doi.org/10.2147/CEG.S72172
83

hp


slow-transit constipation. Activation of 5-hydroxytryptamine type $4\left(5-\mathrm{HT}_{4}\right)$ receptors on cholinergic nerve endings in the enteric nervous system or acetylcholinesterase inhibitors enhances the release of acetylcholine (ACh) from motor neurons, thereby stimulating gastrointestinal propulsive motility. From these pharmacological observations, 5-HT receptor agonists are mainly developed, and other gastric prokinetic agents such as dopamine receptor antagonists have also been developed. Dopamine receptor antagonists such as domperidone are effective for treatment of gastroparesis or nausea, but induce extrapyramidal syndrome and increase plasma prolactin levels as adverse effects. Non-selective $5-\mathrm{HT}_{4}$ receptor agonists such as cisapride were subsequently withdrawn from the global market in 2000 because of their cardiovascular adverse events. A newer generation of selective $5-\mathrm{HT}_{4}$ receptor agonists such as mosapride is being developed for the treatment of chronic gastritis. We have looked forward to the effective oral prokinetic agent with no adverse effect for long time.

\section{Pharmacological data of acotiamide}

Acotiamide is a new prokinetic agent which performs its gastroprokinetic function by enhancing ACh release by acting as an antagonist of the $\mathrm{M}_{1}$ and $\mathrm{M}_{2}$ muscarinic receptors in the enteric nervous system and inhibiting acetylcholinesterase activity (Figure 1). ${ }^{5,6}$ It is known that acotiamide has various pharmacological effects on the gastrointestinal tract. Acotiamide enhances electrically stimulated contractions and the release of Ach in the $\left[{ }^{3} \mathrm{H}\right]$-choline-preincubated gastric antrum and body at doses $>10^{-6} \mathrm{M}$ from a guinea pig's stomach in vitro. Acotiamide reversibly inhibits human erythrocyte $\mathrm{AChE}$ activity, although the $\mathrm{IC}_{50}$ is approximately

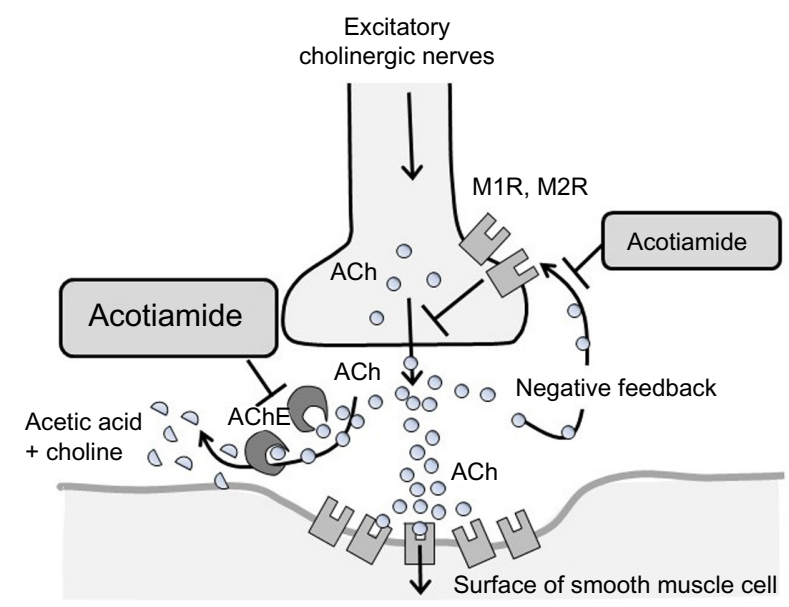

Figure I Pharmacologically effective site of acotiamide.

Abbreviations: $\mathrm{ACh}$, acetylcholine; $\mathrm{AChE}$, acetylcholinesterase; MIR, muscarinic acetylcholine receptor $\mathrm{ml;}$ M2R, muscarinic acetylcholine receptor $\mathrm{m} 2$.
100 -fold less than that of neostigmine and physostigmine. ${ }^{7}$ Receptor-binding studies have shown that acotiamide has affinity for the dopamine $\mathrm{D}_{2}$ receptor but not for the serotonin $5-\mathrm{HT}_{2}, 5-\mathrm{HT}_{3}$, or $5-\mathrm{HT}_{4}$ receptors. Perhaps one mechanism acotiamide facilitates ACh release from cholinergic nerve terminals is by blocking presynaptic muscarinic $\mathrm{M}_{1}$ and $\mathrm{M}_{2}$ autoreceptors. ${ }^{8}$

It had been reported that acotiamide altered the expressions of stress-related genes such as GABA receptors, GABA transporters, and neuromedin $U$ in medulla oblongata or hypothalamus in restrain stress rats. ${ }^{9}$ It suggests that acotiamide has potential role in the regulation of stress through the hypothalamic-pituitary-adrenocortical axis activity.

\section{Trends in clinical trials}

The total number of clinical trials using acotiamide that are registered in PubMed and Japan Medical Abstracts Society continue to grow from year to year (Figure 2). From 2011 to 2014 , the total number of trials increased by more than three times. Reports written in Japanese were significantly increased after the launch of acotiamide for the treatment of FD in 2013.

\section{Systematic review}

Systematic review and meta-analysis about the efficacy of acotiamide on FD has been reported by Xiao et al. ${ }^{3}$ In the meta-analysis, six publications including seven randomized controlled trials were evaluated. ${ }^{5,10-12}$ The summary risk ratio of overall improvement of FD symptoms in

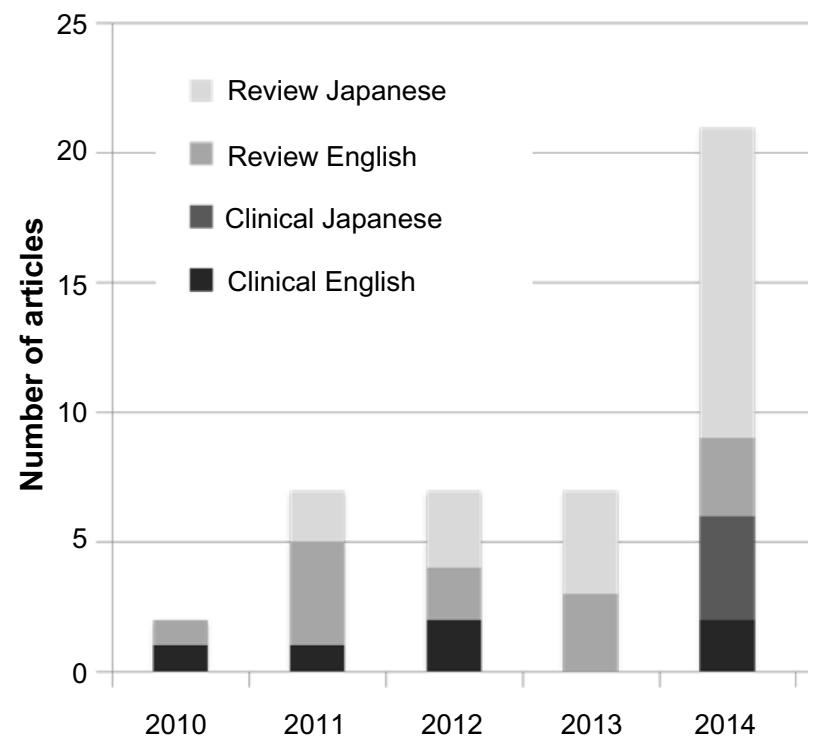

Figure 2 Number of scientific articles on acotiamide published between 2010 and 2014. 
patients receiving acotiamide vs placebo was $1.29(95 \%$ confidence interval [CI] 1.19-1.40, $P<0.00001)$. The risk ratio of improvement of patients with PDS was $1.29(95 \%$ CI: $1.09-1.53, P=0.003)$ and epigastric pain syndrome was 0.92 (95\% CI: 0.76-1.11, $P=0.39$ ). Adverse events were not significantly different between both groups. Acotiamide had the potential to relieve the symptoms of patients with FD, particularly of patients with PDS without major adverse events.

\section{Determination of optimal dose of acotiamide for FD}

A multicenter, randomized, double-blind, placebo-controlled Phase II study of acotiamide was conducted. This Phase II study enrolled 71 patients who had moderate-to-severe symptoms of FD diagnosed using the Rome II criteria. ${ }^{11}$ They were allocated to either of four procedures, namely placebo, 50,100 , or $300 \mathrm{mg}$ acotiamide before meals for 21 days. The 9 week study consists of 3 phases: 2 weeks to washout and evaluate baseline, 3 weeks for medication, and 4 weeks for follow-up. ${ }^{9}$ Symptoms (upper abdominal pain, upper abdominal discomfort, postprandial fullness, upper abdominal bloating, early satiety, nausea, vomiting, excessive belching, and heartburn) were recorded by diary cards. In the $100 \mathrm{mg}$ group, improvement of the overall symptom score was observed in the 2 nd week, along with upper abdominal bloating improving in the 2nd and 3rd week, and heartburn in the 2 nd week.

As shown in Table 1, another Phase II study was carried out in Japan. ${ }^{10}$ This study included two randomized, double-blind, placebo-controlled, parallel-group comparative trials with moderate-to-severe FD patients. Patients with heartburn as a dominant symptom were excluded. In these trials, a randomized controlled treatment period lasted for 28 days, during which a placebo or different doses of acotiamide were allocated to patients during 4 weeks. Study 1: 323 patients were randomized to a placebo group, $100 \mathrm{mg}$ group and 300mg group. Eight upper-abdominal symptoms (upper abdominal pain, upper abdominal discomfort, postprandial fullness, upper abdominal bloating, early satiety, nausea, vomiting, and excessive belching) were recorded. Improvement rate of the overall symptoms was $41.7 \%$ in the placebo group, $51.5 \%$ in $100 \mathrm{mg}$ the group, and $38.1 \%$ in the $300 \mathrm{mg}$ group. The $100 \mathrm{mg}$ group looks better for improvement rates, but there were no statistically significant difference. Elimination rate of postprandial fullness was $28.1 \%$ in the placebo group, $45.2 \%$ in the $100 \mathrm{mg}$ group, and $38.1 \%$ in the $300 \mathrm{mg}$ group, the $100 \mathrm{mg}$ group was significantly higher compared with that of the placebo group. Study 2: 462 patients were randomized to placebo group, $100 \mathrm{mg}$ group, and 300mg group. Improvement rate of overall symptoms were $49.1 \%$ in the placebo group, $48.7 \%$ in the $50 \mathrm{mg}$ group, $58.3 \%$ in the $100 \mathrm{mg}$ group, and $56.9 \%$ in the $300 \mathrm{mg}$ group. $50 \mathrm{mg}$ was not enough, and the $100 \mathrm{mg}$ group results were the best. However, there were no significant difference between the $100 \mathrm{mg}$ group and placebo. The elimination rate of postprandial fullness was $18.3 \%$ in the placebo group, $27.4 \%$ in the $50 \mathrm{mg}$ group, $37.0 \%$ in the $100 \mathrm{mg}$ group, and $30.6 \%$ in the $300 \mathrm{mg}$ group. The results of the 100 and $300 \mathrm{mg}$ groups were significantly better compared with the placebo group. Regarding adverse effects, headache, diarrhea, and increased prolactin were reported, and the incidents were low and not significantly different among the groups. These trials showed that acotiamide was efficient in relieving FD symptoms, especially postprandial fullness, and $100 \mathrm{mg}$ was determined as its optimal dose.

Table I Clinical trials for the efficacy of acotiamide

\begin{tabular}{|c|c|c|c|c|c|}
\hline Author & Trial & Number (analyzed) & Period (weeks) & $\begin{array}{l}\text { Improvement rate } \\
\text { in the acotiamide (\%) }\end{array}$ & $\begin{array}{l}\text { Improvement rate } \\
\text { in the placebo (\%) }\end{array}$ \\
\hline Matsueda et al $^{10}$ & RCT Phase II & $425(307)$ & 4 & $\begin{array}{l}51.5(100 \mathrm{mg}) \\
49.5(300 \mathrm{mg})\end{array}$ & 41.7 \\
\hline Matsueda et al ${ }^{10}$ & RCT Phase II & $731(446)$ & 4 & $\begin{array}{l}48.7(50 \mathrm{mg}) \\
58.3(100 \mathrm{mg}) \\
56.7(300 \mathrm{mg})\end{array}$ & 49.1 \\
\hline Matsueda et al ${ }^{12}$ & RCT Phase III & I,394 (850) & 9 & 52.2 & 34.8 \\
\hline Matsueda et $a^{13}$ & $\begin{array}{l}\text { Single-arm Phase II } \\
\text { Long-term study }\end{array}$ & $582(409)$ & $24-48$ & $\begin{array}{l}60.6 \text { (8 weeks) around } \\
60 \text { ( } 24-48 \text { weeks) }\end{array}$ & N/A \\
\hline Mayanagi et al'14 & $\begin{array}{l}\text { Phase II } \\
\text { Add acotiamide to PPI }\end{array}$ & $105(23)$ & 2 & 78 & $\mathrm{~N} / \mathrm{A}$ \\
\hline Adam et $\mathrm{al}^{16}$ & RCT Phase II crossover & 57 & $\begin{array}{l}7-9 \text { days with } \\
2 \text { weeks washout }\end{array}$ & $\begin{array}{l}\text { Improvement ratio in FD } \\
35\end{array}$ & $\begin{array}{l}\text { Improvement ratio } \\
\text { in control } 23\end{array}$ \\
\hline
\end{tabular}

Abbreviations: FD, functional dyspepsia; PPI, proton pump inhibitor; RCT, randomized controlled trial; N/A, not applicable. 


\section{Phase III study}

In a Phase II study, acotiamide had an improvement effect on postprandial fullness, upper abdominal distension, and early satiation. A Phase III trial ${ }^{12}$ (Table 1) was conducted as a randomized, double-blind, placebo-controlled, parallelgroup comparative study, which examined the advantages of the placebo effect on patients who had the following symptoms: postprandial fullness, upper abdominal distension, and early satiation. The primary efficacy end points were global assessment of overall treatment efficacy and elimination rate of all of three meal-related symptoms. Secondary efficacy end points were symptom scores and quality of life. The trial period was a total of 9 weeks: 1 week for observing the eligibility of patients, 4 weeks for treating and observing efficacy and safety of procedures, and 4 weeks for investigating a patient's conditions, including the transition of FD after treatment. The final analyzed number of cases was 892 (placebo 442 cases vs acotiamide $100 \mathrm{mg} 450$ cases).

The improvement rate of patient's symptom was $34.8 \%$ in the placebo group and $52.2 \%$ in the acotiamide group. The rate of elimination of three symptoms on the last investigation point was $9.0 \%$ in the placebo group and $15.3 \%$ in the acotiamide group. Improvement rate of both the patient's impression and the elimination rate of three symptoms were significantly higher in the acotiamide group than in the placebo group. Regarding secondary endpoint, the improvement rate of patients' impression on each investigation point increased by a time-dependent manner from 1 st to 4 th week, $35.0 \%$ in the placebo and $53.1 \%$ in the acotiamide group at the 4th week into the treatment period. In the posttreatment period, the improvement effect on the 4th week was maintained. At each investigation point, improvement rates of the acotiamide group was significantly higher than placebo group from 2nd to 4th week in the treatment period and 1 st to 4th week in the after observation period. The elimination rate of three symptoms at each investigation point was increased sequentially both in the placebo and $100 \mathrm{mg}$ groups from $1 \mathrm{st}$ to 4 th week of the treatment period, and the rate was $9.1 \%$ in the placebo group and $15.4 \%$ in the $100 \mathrm{mg}$ group at the 4th week. Symptom elimination effect was maintained with almost the same level at the 4th week in the posttreatment period. On each investigation point, patients' impression in the $100 \mathrm{mg}$ group was significantly higher than placebo group from the 3 rd to 4 th week in the treatment period and 1 st to 4th week compared between placebo groups. Regarding the patient's QOL, the variates from mean value of the Short-Form Nepean Dyspepsia Index scale (total value of five domain mean value) in the observation period were as follows: -2.84 in the placebo group and -3.66 in the acotiamide group in the treatment period, -3.01 in the placebo group and -3.83 in the acotiamide group in the posttreatment period. In both the treatment period and posttreatment period, the QOL of the $100 \mathrm{mg}$ group was significantly improved compared with the placebo group. These results suggested that acotiamide maintains the improvement of QOL. From the above findings, the efficacy of acotiamide for FD was confirmed.

\section{Other clinical studies}

Several reports about the clinical practice of acotiamide have been published recently in Japan. A multicenter, open-label, single-arm, long-term (48 weeks) study with acotiamide $100 \mathrm{mg}$ tid was conducted after Phase III trial in Japan on patients with FD, who had postprandial fullness, upper abdominal distension, and early satiation, which fulfilled Rome III criteria. ${ }^{13}$ The primary endpoint of the study was the impression of patients (seven-grade evaluation) at each investigation point and elimination of three symptoms within 8 weeks. The main secondary endpoint was elimination of each symptom at each investigation point. The trial period included 1 week to confirm the eligibility of patients and 24 weeks (the longest 48 weeks) to evaluate efficacy, safety, and favor medication patterns. A total of 409 patients were administered to take the investigational drug, and 405 patients were subjected for final analysis. The percent improvement of patient's symptom was $48.9 \%$ at the 4 th week of treatment period. Also, after the 5 th week, the percent improvement was at the same level as the 4 th week. The percent improvement was $66.7 \%$ at the 48 th week and $73.2 \%$ during the last period of treatment. The elimination rate of three symptoms was $7.1 \%$ at the 4 th week of the treatment period. After the 5 th week of the treatment period, the elimination rate increased and was at $10.9 \%$ during the 8 th week of treatment period as well as the last investigation point. As a result of investigating medication patterns, withdrawal was $75.1 \%$ against criteria. The mean medication days from the first withdrawal was 60.4 , and the mean remedication days was 55.7 from the first remedication to secondary withdrawal; $38.0 \%$ was withdrawal after elimination of symptoms and most of the patients were suggested maintenance of the effect after withdrawal. On the other hand, $13.6 \%$ patients were discontinued due to invalid results. From the above results, maintenance of improvement effect after withdrawal of acotiamide was suggested. Moreover, it was thought that second improvement was acquired when patients resumed medication even the symptoms relapsed after withdrawal of acotiamide. 
The combined therapy of a proton pump inhibitor and acotiamide for a refractory patient of FD was reported (Table 1). ${ }^{14}$ In this study, the overall symptomatic improvement rate was $78 \%$. Almost all FD-related symptoms significantly improved in not only patients with PDS, but also in patients with epigastric pain syndrome. It suggests that combined therapy of proton pump inhibitor and acotiamide will be a good therapeutic option for refractory patients of FD.

The effect of a single administration of acotiamide on gastric emptying using a ${ }^{13} \mathrm{C}$ breath test in healthy adult humans was examined. ${ }^{15}$ Healthy adult humans were administrated $100 \mathrm{mg}$ or $300 \mathrm{mg}$ of acotiamide orally by a double-blind, crossover to placebo manner. This study showed no significant difference in the gastric emptying among the three groups. A single administration of acotiamide had no effect on gastric empting, suggesting that the beneficial effect of acotiamide in patients with FD not resulted from accelerating gastric emptying.

Therefore, other reports suggested the beneficial effect of acotiamide was shown only in FD patients and not in healthy volunteer in clinical studies (Table 1). ${ }^{16}$ In animal study, acotiamide significantly improved both delayed gastric emptying and feeding inhibition in restraint stress-induced model, but did not affect both normal gastric emptying and feeding in intact rats, indicating acotiamide exerted effects only on gastric emptying and feeding impaired by restrain stress. ${ }^{9}$ These results suggest that the positive effect of acotiamide in patients with FD is not based on enhancing gastric emptying but on restoring delayed gastric emptying by stress.

The positive effect of acotiamide on both gastric emptying and gastric accommodation using ultrasound during a drinking test was reported in Japan. ${ }^{5}$ Rome II criteria-defined FD patients were randomized to receive either placebo or acotiamide in a double-blind controlled randomized fashion and both examined the ultrasonography before and 14-18 days after the administration. Gastric accommodation rate after overnight fasting was assessed on the cross-sectional area of the proximal stomach using ultrasonography for every $100 \mathrm{~mL}$ ingestion of a test meal. Gastroduodenal emptying rate was assessed with a ultrasound probe positioned on the cross-sectional antrum after $400 \mathrm{~mL}$ ingestion of the test meal. Gastric accommodation and gastric emptying in acotiamide group were significantly enhanced compared with those in placebo group.

\section{Clinical dose of acotiamide}

The dose of acotiamide $100 \mathrm{mg}$ tid showed a consistent efficacy for the overall improvement of FD symptoms. ${ }^{3}$ The relatively high improvement rate of FD symptoms in patients who took acotiamide $100 \mathrm{mg}$ tid was found in a multicenter, single-arm, long-term (48 weeks), Phase III study ${ }^{13}$ and another 4-week Phase III randomized controlled trial. ${ }^{12}$ These certain results indicate that the dose of $100 \mathrm{mg}$ tid is the most suitable dosage of acotiamide in the treatment of FD. On the other hand, there was no dose-response relationship between dosages of acotiamide and the efficacy in the treatment of FD or gastric emptying. ${ }^{15}$

\section{Conclusion}

Given the known study to date, it appears acotiamide has been proven to be helpful for FD patients. Acotiamide was more effective than placebo in improving symptoms, and QOL received $100 \mathrm{mg}$ of acotiamide three times a day for 4 weeks in a Phase III trial. Acotiamide has been available in Japan since 2013, and significant adverse events have not been reported. Clinical trials have been conducted in Europe and the USA. Acotiamide has potential to be a promising gastroprokinetic agent for FD because of its efficacy without any significant adverse events. ${ }^{17}$

\section{Disclosure}

During the last 2 years, Author HS received scholarship funds for the research from Astellas Pharm Inc., Astra-Zeneca K.K., Otsuka Pharmaceutical Co. Ltd, Shionogi \& Co. Ltd, Takeda Pharmaceutical Co. Ltd, and Zeria Pharmaceutical Co. Ltd; received service honoraria from Astellas Pharm Inc., Astra-Zeneca K.K., Otsuka Pharmaceutical Co. Ltd, Takeda Pharmaceutical Co. Ltd, and Zeria Pharmaceutical Co. Ltd; and played a role for advisory board members for AstraZeneca K.K. and Takeda Pharmaceutical Co. Ltd. The other authors report no conflicts of interest in this work.

\section{References}

1. Altan E, Masaoka T, Farre R, Tack J. Acotiamide, a novel gastroprokinetic for the treatment of patients with functional dyspepsia: postprandial distress syndrome. Expert Rev Gastroenterol Hepatol. 2012;6(5):533-544.

2. Suzuki H, Hibi T. Acotiamide (Z-338) as a possible candidate for the treatment of functional dyspepsia. Neurogastroenterol Motil. 2010;22(6):595-599.

3. Xiao G, Xie X, Fan J, et al. Efficacy and safety of acotiamide for the treatment of functional dyspepsia: systematic review and meta-analysis. ScientificWorldJournal. 2014;2014:1-9.

4. Sanger GJ, Alpers DH. Development of drugs for gastrointestinal motor disorders: translating science to clinical need. Neurogastroenterol Motil. 2008;20(3):177-184.

5. Kusunoki H, Haruma K, Manabe N, et al. Therapeutic efficacy of acotiamide in patients with functional dyspepsia based on enhanced postprandial gastric accommodation and emptying: randomized controlled study evaluation by real-time ultrasonography. Neurogastroenterol Motil. 2012;24(6):540-545, e250-e541.

6. Tack J, Talley NJ, Camilleri M, et al. Functional gastroduodenal disorders. Gastroenterology. 2006;130(5):1466-1479. 
7. Ueki S, Matsunaga Y, Matsumura T, et al. Z-338, a novel prokinetic agent, stimulates gastrointestinal motor activity and improves delayed gastric emptying in the dog and rat. Naunyn Schmiedebergs Arch Pharmacol. 1998;358:R351.

8. Ogishima M, Kaibara M, Ueki S, Kurimoto T, Taniyama K. Z-338 facilitates acetylcholine release from enteric neurons due to blockade of muscarinic autoreceptors in guinea pig stomach. J Pharmacol Exp Ther. 2000;294(1):33-37.

9. Seto K, Sasaki T, Katsunuma K, Kobayashi N, Tanaka K, Tack J. Acotiamide hydrochloride (Z-338), a novel prokinetic agent, restores delayed gastric emptying and feeding inhibition induced by restraint stress in rats. Neurogastroenterol Motil. 2008;20(9):1051-1059.

10. Matsueda K, Hongo M, Tack J, Aoki H, Saito Y, Kato H. Clinical trial: dose-dependent therapeutic efficacy of acotiamide hydrochloride (Z-338) in patients with functional dyspepsia-100 $\mathrm{mg}$ tid is an optimal dosage. Neurogastroenterol Motil. 2010;22(6):e618-e173.

11. Tack J, Masclee A, Heading R, et al. A dose-ranging, placebo-controlled, pilot trial of acotiamide in patients with functional dyspepsia. Neurogastroenterol Motil. 2009;21(3):272-280.

12. Matsueda K, Hongo M, Tack J, Saito Y, Kato H. A placebo-controlled trial of acotiamide for meal-related symptoms of functional dyspepsia. Gut. 2012;61(6):821-828.
13. Matsueda K, Hongo M, Ushijima S, Akiho H. A long-term study of acotiamide in patients with functional dyspepsia: results from an open-label phase III trial in Japan on efficacy, safety and pattern of administration. Digestion. 2011;84(4):261-268.

14. Mayanagi S, Kishino M, Kitagawa Y, Sunamura M. Efficacy of acotiamide in combination with esomeprazole for functional dyspepsia refractory to proton-pump inhibitor monotherapy. Tohoku J Exp Med. $2014 ; 234(3): 237-240$.

15. Zai H, Matsueda K, Kusano M, Urita Y, Saito Y, Kato H. Effect of acotiamide on gastric emptying in healthy adult humans. Eur J Clin Invest. 2014;44(12):1215-1221.

16. Adam B, Liebregts T, Zschau NB, et al. Z-338 improves meal-induced symptoms in functional dyspepsia: a double-blind, randomized, placebo controlled crossover study. Gastroenterology. 2009;136(5):A535.

17. Matsushita M, Masaoka T, Suzuki H. Emerging treatments in neurogastroenterology: Acotiamade, a novel treatment option for functional dyspepsia. Neurogastroenterol Motil. Epub 2016 Jan 5.

\section{Publish your work in this journal}

Clinical and Experimental Gastroenterology is an international, peerreviewed, open access journal, publishing all aspects of gastroenterology in the clinic and laboratory, including: Pathology, pathophysiology of gastrointestinal disease; Investigation and treatment of gastointestinal disease; Pharmacology of drugs used in the alimentary tract;
Immunology/genetics/genomics related to gastrointestinal disease. This journal is indexed on CAS. The manuscript management system is completely online and includes a very quick and fair peer-review system. Visit http://www.dovepress.com/testimonials.php to read rea quotes from published authors.

Submit your manuscript here: http://www.dovepress.com/clinical-and-experimental-gastroenterology-journal 